\title{
Parents' willingness to have their child receive care by physician assistants in a pediatric emergency department
}

\author{
Quynh Doan, MDCM, MHSc*; Sam Sheps, MD, $\mathrm{MSc}^{\dagger}$; Hubert Wong, $\mathrm{PhD}^{\dagger}$; Joel Singer, $\mathrm{PhD}^{\dagger}$; \\ David Johnson, MD, MSc ${ }^{\ddagger}$; Niranjan Kissoon, MD§
}

\begin{abstract}
Objective: To determine the willingness of parents of children visiting a pediatric emergency department to have a physician assistant (PA) assess and treat their child and the waiting time reduction sufficient for them to choose to receive treatment by a PA rather than wait for a physician. Method: After describing the training and scope of practice of PAs, we asked caregivers of children triaged as urgent to nonurgent if they would be willing to have their child assessed and treated by a PA on that visit: definitely, maybe, or never. We also asked the minimum amount of waiting time reduction they would want to see before choosing to receive treatment by a PA rather than wait for a physician. Result: We approached 320 eligible subjects, and 273 (85.3\%) consented to participate. Regarding whether they would be willing to have their child receive treatment by a PA, 140 $(51.3 \%)$ respondents answered definitely, 107 (39.2\%) said maybe, and 26 (9.2\%) said never. Most respondents (64.1\%) would choose to have their child seen by a PA instead of waiting for a physician if the waiting time reduction were at least 60 minutes (median 60 minutes [interquartile range 60 minutes]). Respondents' perception of the severity of their child's condition was associated with unwillingness to receive treatment by a $\mathrm{PA}$, whereas child's age, presenting complaint, and actual waiting time were not.

Conclusion: Only a small minority of parents of children visiting a pediatric emergency department for urgent to nonurgent issues are unwilling to have their child treated by PAs.
\end{abstract}

\section{RÉSUMÉ}

Objectifs: L'étude visait à déterminer dans quelle mesure des parents étaient disposés à voir leur enfant examiné et traité par un assistant médecin (AM) au service des urgences pédiatriques, et à quantifier le gain minimal de temps pour que ceux-ci acceptent de rencontrer un AM plutôt qu'un médecin.

Méthode: Après avoir décrit la formation des AM et l'étendue de leur pratique, nous avons demandé à des parents d'enfants considérés comme des cas urgents, moins urgents, ou non urgents s'ils accepteraient de voir leur enfant évalué et traité par un AM pour la consultation en cours selon l'échelle suivante: certainement, peut-être, jamais. Nous leur avons également demandé combien de temps ils devraient gagner au minimum pour qu'ils acceptent de rencontrer un AM plutôt qu'un médecin.

Résultats: Sur 320 sujets admissibles, 273 (85.3\%) ont accepté de participer à l'étude. En ce qui concerne le consentement des parents à voir leur enfant traité par un $\mathrm{AM}, 140$ (51.3\%) ont répondu certainement; 107 (39.2\%), peut-être; et $26(9.2 \%)$, jamais. La plupart des parents $(64.1 \%)$ ont répondu qu'ils préféreraient voir leur enfant examiné par un AM plutôt que d'attendre un médecin si le gain de temps était d'au moins 60 minutes (attente médiane: 60 minutes [intervalle interquartile: 60 minutes]). La perception du degré de gravité de la maladie par les répondants a été associée au refus de voir l'enfant traité par un $A M$, contrairement à d'autres facteurs tels que l'âge de l'enfant, le principal motif de consultation, et le délai réel d'attente.

Conclusion: Seul un petit nombre de parents ne s'est pas montré disposé à voir leur enfant traité par un AM pour des problèmes de santé dont le degré de gravité variait d'urgent à non urgent au service des urgences pédiatriques.

Keywords: acceptance, pediatric emergency medicine, physician assistants

Many children present to pediatric emergency departments (EDs) with nonurgent conditions. ${ }^{1,2}$ Reliance on

From the *Department of Pediatrics, Child and Family Research Institute, University of British Columbia, and Emergency Department, BC Children's Hospital, Vancouver, BC; †School of Population and Public Health, University of British Columbia, Vancouver, BC; of Calgary, and Alberta Children's Hospital, Calgary, AB; and §Department of Pediatrics, University of British Columbia.

Correspondence to: Dr. Quynh Doan, Emergency Department, BC Children's Hospital, University of British Columbia, 4480 Oak Street, Vancouver, BC V6H 3V4; qdoan@shaw.ca.

This article has been peer reviewed.

(c) Canadian Association of Emergency Physicians
CJEM 2013:15(6):330-336

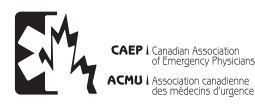

DOI 10.2310/8000.2013.130745

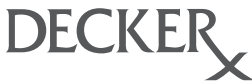


specialist physicians, including emergency pediatricians, to evaluate and treat both urgent and nonurgent concerns is neither efficient nor sustainable. An alternative resource, physician assistants (PAs), has been developing and debated in Canada since the early 1990s. s. $^{3-5}$

The use of PAs in EDs is common in the United States and has resulted in high patient satisfaction and acceptance by other health care providers. ${ }^{6-8}$ In Canada, PAs are now trained at Manitoba University, where a master's program is offered, as well as at McMaster University, where it is offered as an undergraduate program. PAs are physician extenders, with their roles being tailored to specific clinical needs to assist physicians. PAs' scope of practice includes complete patient assessment, initiation of clinical investigations, and patient treatment under relative physician supervision. Using a PA to assist in managing nonurgent, low-complexity cases may reduce waiting times in a pediatric ED.

There is growing interest in introducing PAs into the Canadian health care system as a means to enhance timely access to health care services. ${ }^{9}$ Their deployment into Ontario EDs, for example, appears to have improved patient flow. ${ }^{10}$

Studies of health care users' willingness to be treated by PAs have shown conflicting results. In an American study, only $57 \%$ were willing to be treated by a PA, ${ }^{11}$ whereas a study in Australia found that over 99\% of respondents were willing to be treated by a PA. ${ }^{12} \mathrm{~A}$ similar survey to the Australian study, in Vancouver, British Columbia, ${ }^{13}$ found that when faced with hypothetical injury scenarios and a 4-hour wait to see a physician, adults chose to be treated by the PA 85 to $99 \%$ of the time, depending on a time to PA that ranged from 30 minutes to 2 hours. When asked about an injury scenario involving their child, however, only 67 to $96 \%$ of parents chose to be seen by a PA. The aversion of parents to an unfamiliar type of health care provider for their children is a complex and important notion to explore. This study explored Canadians' acceptance of a PA providing care to their child in a pediatric ED setting and the trade-off in waiting time reduction expected for not being assessed and treated by an emergency pediatrician.

\section{METHODS}

We conducted a cross-sectional survey between July 9, 2010, and March 15, 2011, at the British Columbia
Children's Hospital, a tertiary care pediatric hospital in Vancouver with over 40,000 ED visits annually.

We surveyed adults ( $>17$ years old) seeking care for a child at the ED triaged to level 3 (urgent), 4 (semiurgent), or 5 (nonurgent) using the pediatric Canadian Triage and Acuity Scale (CTAS). This inclusion criterion was based on a previous survey of emergency pediatricians at our hospital that concluded that three-quarters of patient visits triaged CTAS 3 to 5 would be appropriate for management by PAs with variable physician supervision. ${ }^{14}$

After consent, participants were given a brief, written description of PA training and scope of practice and told that PAs did not currently work in the ED (Appendix). They were then told the following:

You have been selected for participation into this study because the reason for your/your child's visit and your/your child's general condition are within the range of conditions that physician assistants commonly manage in their practice. We would like you to imagine that PAs were working here and that they could see you/your child, order required tests, provide treatment and give you discharge instructions when you/your child can safely go home, or consult the physician if your/your child's condition needed it.

We then asked, "Would you then be willing to receive treatment from a PA? Definitely, maybe or never." We also asked, "If seeing a PA could get you/ your child seen sooner than being seen by a physician, how much of waiting time reduction would be enough for you to choose to receive treatment from a PA rather than wait for a physician?" Respondents were also asked to select from a list of 30-minute intervals ranging from 30 to $>240$ minutes. In addition, we recorded the child's age, presenting complaint, CTAS category, respondent's relation to the patient and perception of the severity of the child's condition (mild, moderate, or severe), and whether the child had already been seen by a physician at the time of the survey. We also calculated the actual waiting time to see a physician from health records after the visit as a surrogate for the department activity level.

Our primary outcome was the proportion of subjects who were definitely or possibly willing to consider having their child seen and treated by a PA. We also wondered what waiting time reduction would be felt necessary for that trade-off. 
After combining respondents who selected "yes" and "maybe" into one category, "willing," we used binomial logistic regression analysis ( $S A S$ version 9.2; SAS Institute Inc, Cary, NC) to assess the association between perceived severity of the child's illness, child's age, presenting complaint, pediatric CTAS triage category, and actual waiting time on the likelihood of considering care by a PA. We used Firth's penalized likelihood method to correct for separation where present. ${ }^{15}$ A planned sample size of 270 participants was chosen to achieve $\pm 5 \%$ precision, with $90 \%$ confidence in the estimate of the proportion of subjects considering having a PA see their child being $50 \%$, the proportion resulting in the most conservative (largest) sample size requirement. This study was approved by the Vancouver Children's \& Women's Health Centre Research Review Committee and the University of British Columbia Behavioural Research Ethics Board. All subjects provided signed informed consent.

\section{RESULTS}

We approached 320 eligible participants, among whom 28 declined to participate and 19 were unable to provide informed consent due to language barriers. We enrolled 273 participants (participation rate $85.3 \%$ ).

When asked if they would be willing to have their child seen and treated by a PA and only subsequently by a physician if the child's condition needed it, 140 $(51.3 \%)$ respondents answered definitely, 107 (39.2\%) answered maybe, and $26(9.2 \%)$ responded no (Table 1). CTAS triage level and perceived severity of the child's condition were associated with willingness to be assessed and managed by a PA, whereas other subject and child characteristics were not (Table 2).

A large majority of respondents were willing to be seen by a PA rather than a physician if the reduction in waiting time was at least 90 minutes (Figure 1). The median waiting time trade-off selected was 60 minutes (interquartile range [IQR] 60 minutes). The median actual waiting time was 93 minutes (IQR 75 minutes).

\section{DISCUSSION}

The British Columbia Ministry of Health, in conjunction with the BC Medical Association and College of Physicians and Surgeons of BC, is contemplating the introduction of PAs into the health care system. Among the myriad of issues raised, it is important to explore health care users' acceptance of PAs as providers. Our study suggests that the majority of parents of children seen in the ED for nonemergent causes would be possibly or definitely willing to receive treatment by a PA. This result provides some support for broadening the front-line resource mix in a pediatric ED. A few parents were unwilling to have their child treated by a PA, however. Most of these had children triaged as CTAS 3 and perceived their child's condition to be moderate to severe. These findings are consistent with a survey of emergency pediatricians on the clinical presentations felt to be appropriate for PAs, with fewer CTAS level 3 conditions. ${ }^{14}$

In a similar study in a general ED in Vancouver, Moser and colleagues found that $72.5 \%$ of respondents were willing to be treated by a nurse practitioner, among whom $21 \%$ also expected to be seen by a physician in addition to the nurse practitioner. ${ }^{16}$ Among those unwilling to be treated by a nurse practitioner, $37.5 \%$ would reconsider if it meant a shorter waiting time. Both studies are limited by the fact that respondents may not have had previous experience with nonphysician clinicians and are providing an opinion based on a description of the nonphysician clinician's scope of practice in a hypothetical situation. Although our study differed in that we investigated parents' willingness to have their child treated by PAs when visiting the pediatric ED for nonemergent complaints, while they determined the attitudes of ED patients toward nurse practitioners, this difference may not be important in the eyes of health care users.

PAs and nurse practitioners are often compared and in certain contexts can serve the same role, depending on the individual and his or her flexibility. The main difference is that the scope of practice of nurse practitioners allows them to be independent health care providers. They often practice in community care settings and function as an alternative to physicians. PAs, however, often appear to practice independently and are linked to a supervising physician, and the degree of supervision (from side-by-side work to offsite support through telephone access) is left to the PAphysician pair's discretion.

The more important differences between these two studies are the population to be treated (adults versus children). In addition, less than $50 \%$ of respondents (101 of 207) in the Moser and colleagues study were willing to be treated by the nurse practitioner without the expectation of also being seen by a physician, ${ }^{16}$ whereas respondents to our survey were instructed that 
Parents' willingness to have child receive PA care in the ED

\begin{tabular}{|c|c|c|c|}
\hline Independent variable (\%) & $\begin{array}{l}\text { Not willing to have child } \\
\text { managed by PA }\end{array}$ & $\begin{array}{c}\text { Possibly willing to have child } \\
\text { managed by PA }\end{array}$ & $\begin{array}{c}\text { Definitely willing to } \\
\text { have child managed } \\
\text { by PA }\end{array}$ \\
\hline \multicolumn{4}{|l|}{ Age $(y r)$} \\
\hline$<1$ & $3(11.5)$ & $14(13.1)$ & $14(10.1)$ \\
\hline $1-4.99$ & $6(23.1)$ & $46(43.0)$ & $45(32.6)$ \\
\hline $5-11.99$ & $12(46.2)$ & $33(30.8)$ & $56(40.6)$ \\
\hline $12-17$ & $5(19.2)$ & $14(13.1)$ & $23(16.7)$ \\
\hline \multicolumn{4}{|l|}{ CTAS level } \\
\hline 3 & $18(69.2)$ & $43(40.2)$ & $42(30.4)$ \\
\hline 4 & $7(26.9)$ & $61(57.0)$ & 77 (55.8) \\
\hline 5 & $1(3.9)$ & $3(2.8)$ & $17(12.3)$ \\
\hline \multicolumn{4}{|l|}{ Actual waiting time (min) } \\
\hline Median (IQR) & $94.5(89.4)$ & $100.9(63.9)$ & $90.2(86.9)$ \\
\hline \multicolumn{4}{|l|}{ Chief complaint by system } \\
\hline Musculoskeletal/injury & $6(23.1)$ & $25(23.4)$ & $43(31.6)$ \\
\hline Infectious (fever) & $5(19.2)$ & $31(29.0)$ & $30(22.1)$ \\
\hline Respiratory & $5(19.2)$ & $12(11.2)$ & $10(7.4)$ \\
\hline Abdominal/genitourinary & $8(30.8)$ & $26(24.3)$ & $36(26.5)$ \\
\hline Neurologic & 0 & $10(9.3)$ & $6(4.4)$ \\
\hline Cardiovascular & 0 & $0(0.0)$ & $1(0.7)$ \\
\hline Dermatologic & $2(7.7)$ & $3(2.8)$ & $10(7.4)$ \\
\hline \multicolumn{4}{|l|}{ Respondent's relation to child } \\
\hline Mother & $19(73.1)$ & $70(65.4)$ & $90(65.2)$ \\
\hline Father & $5(19.2)$ & $32(29.9)$ & $40(29.0)$ \\
\hline Other & $2(7.7)$ & $35(4.5)$ & $8(5.8)$ \\
\hline \multicolumn{4}{|c|}{ Respondent's perceived severity of child's condition } \\
\hline Mild & $2(7.7)$ & $16(15.0)$ & $44(31.9)$ \\
\hline Moderate & $16(61.5)$ & $76(71.0)$ & $82(59.4)$ \\
\hline Severe & $8(30.8)$ & $15(14.0)$ & $12(8.7)$ \\
\hline \multicolumn{4}{|l|}{ Status at enrolment } \\
\hline Not yet seen & $15(57.7)$ & $63(58.9)$ & $87(63.0)$ \\
\hline Already seen by physician & $11(42.3)$ & $44(41.1)$ & $51(37.0)$ \\
\hline
\end{tabular}

they would be seen by a physician only if deemed necessary by the PA. Finally, we were able to quantify the magnitude of waiting time reduction valued by respondents as a trade-off for not seeing a physician. A 30-minute reduction in waiting time was sufficient for a third of respondents and a 60-minute reduction for another third to choose to receive treatment by a PA rather than wait for a physician.

A survey using scenarios of hypothetical acute injuries to assess health care users' willingness to be treated by PAs given a shorter waiting time than to see a physician found that respondents were more reluctant to choose a PA and were willing to wait longer to have their child seen by a physician when faced with the case of a child with a forehead laceration, in contrast to their reaction to scenarios involving adults with ankle sprains or forearm lacerations. ${ }^{13}$ Whether this was due to the pediatric nature of the scenario or, more specifically, to the perceived higher severity associated with a head injury is unknown. In contrast, our study found that the perceived severity of the child's condition was strongly and inversely associated with the respondent's willingness to have the child seen by the PA, whereas the type of clinical complaint on presentation to the ED and age were not.

The main limitation of our study is that it was conducted at one centre, an academic pediatric ED, and our findings may not be generalizable to general EDs, where a large proportion of children receive care. Although we cannot extrapolate our findings to general 
Table 2. Association between respondent, patient, and visit characteristics and unwillingness to accept pediatric emergency care treatment by PAs*

\begin{tabular}{|c|c|c|}
\hline Effect & Odds ratio & $95 \% \mathrm{Cl}$ \\
\hline \multicolumn{3}{|l|}{ Age (ref: < 1 year old) } \\
\hline $1-4.99$ & 0.60 & $0.14-2.56$ \\
\hline 5-11.99 & 1.26 & $0.33-4.78$ \\
\hline $12-17$ & 1.26 & $0.28-5.73$ \\
\hline \multicolumn{3}{|l|}{ CTAS level (ref: CTAS 3) } \\
\hline 4 & 0.24 & $0.10-0.59$ \\
\hline 5 & 0.23 & $0.03-1.78$ \\
\hline \multicolumn{3}{|l|}{ Waiting time (ref: $<60 \mathrm{~min}$ ) } \\
\hline $60-119.9$ & 0.51 & $0.13-1.98$ \\
\hline $120-179.9$ & 1.77 & $0.28-11.25$ \\
\hline$\geq 180$ & 0.59 & $0.09-3.95$ \\
\hline \multicolumn{3}{|c|}{ Chief complaint (ref: musculoskeletal/injury) } \\
\hline Infectious (fever) & 0.94 & $0.29-3.12$ \\
\hline Respiratory & 2.54 & $0.73-8.85$ \\
\hline Abdominal/genitourinary & 1.39 & $0.47-4.11$ \\
\hline Neurologic & 0.30 & $0.04-343.62$ \\
\hline Cardiovascular & 3.48 & $0.36-8.90$ \\
\hline Dermatologic & 1.60 & $0.29-8.74$ \\
\hline \multicolumn{3}{|l|}{ Respondent (ref: mother) } \\
\hline Father & 1.72 & $0.62-4.79$ \\
\hline Other & 1.30 & $0.16-10.62$ \\
\hline \multicolumn{3}{|c|}{ Perceived severity (ref: severe) } \\
\hline Moderate & 0.34 & $0.13-0.87$ \\
\hline Mild & 0.11 & $0.02-0.56$ \\
\hline \multicolumn{3}{|l|}{ Seen status (ref: not seen) } \\
\hline Seen & 1.15 & $0.51-2.62$ \\
\hline
\end{tabular}

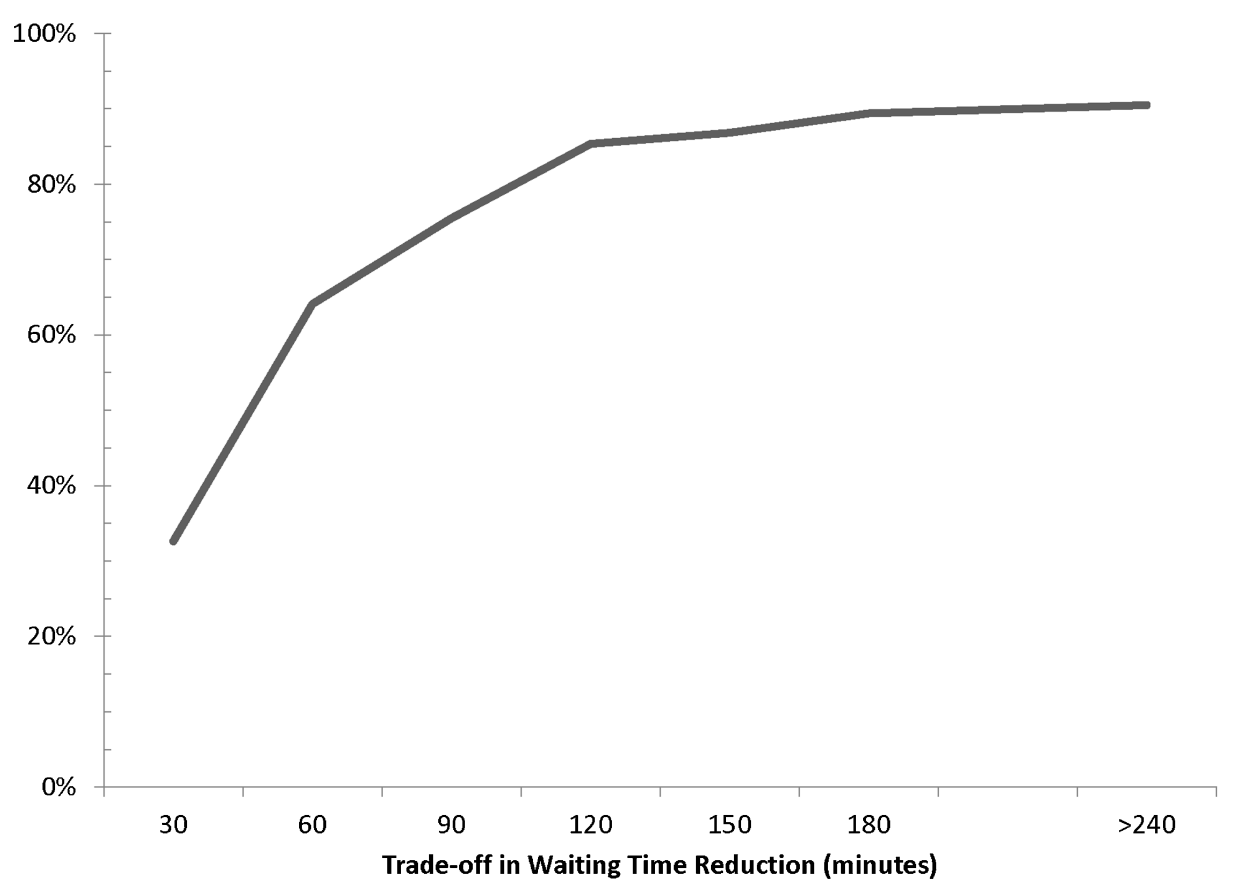

Figure 1. The cumulative proportion of respondents willing to consider being treated by a physician assistant in return for a given reduction in waiting time. 
EDs with any degree of certainty, it is possible—given that some parents seek ED care at children's hospitals expressly to receive subspecialized medical treatmentthat our findings underestimate parents' general willingness to have PAs evaluate their children. In addition, although subjects were given opportunities to ask for more detailed information about PAs, and most appeared comfortable answering the questions pertaining to the survey, we did not formally evaluate participants' understanding of PA roles and scope of practice range. Education level and socioeconomic background were also not assessed in this study. It is possible that such social factors may affect parent's willingness to have their child receive treatment by PAs despite not having to pay out of pocket for health care services. To address this issue, a qualitative study to investigate parental priorities in seeking ED care for their children's nonemergent complaints, and the value they put on the type of health care provider versus timeliness of the initial assessment would add understanding to how PAs would be perceived by caregivers of children treated in EDs. Furthermore, cost-effectiveness, quality of care, and influence on academic programs are factors that will also need to be addressed prior to the introduction of PAs into pediatric EDs.

\section{CONCLUSION}

Our study addressed willingness to accept care by PAs in a pediatric ED population, where PAs are yet to be implemented. Our findings suggest that a minority of parents of children visiting a tertiary care pediatric ED for nonemergent issues are unwilling to have their child treated by PAs and that most would find an hour reduction in waiting time sufficient for them to choose to receive treatment by a PA rather than wait for a physician.

Acknowledgement: We would like to acknowledge the contributions of Mr. Anthony Bryson and Dr. Shiva Tayebi for conducting the patient surveys in the emergency department.

Competing interests: Dr. Q. Doan was supported by a doctoral award from the Canadian Child Health Clinician Scientist Program in completing this work.

\section{REFERENCES}

1. Carret ML, Fassa AG, Kawachi I. Demand for emergency health services: factors associated with inappropriate use.
BMC Health Serv Res 2007;7:131-9, doi:10.1186/1472-6963$\underline{7-131 .}$.

2. Ehrlich NJ, Tasmin F, Safi H, et al. Pilot study of ER utilization at Tulsa hospitals. 7 Okla State Med Assoc 2004;97: 64-8.

3. Brethour I, Carlson G, Patterson G, et al. The physician assistant in primary care: a proposal for British Columbia's health care system. Victoria (BC): BC Ministry of Health; 1994.

4. British Columbia Medical Association. Working together enhancing multidisciplinary primary care in British Columbia: a policy paper by BC's physicians. Vancouver (BC): British Columbia Medical Association; 2005.

5. British Columbia Medical Association. Policy statement. November 2009. Available at: http://www.bcma.org/files/ Physician_Assistants.pdf (accessed June 9, 2011).

6. Counselman FL, Graffeo CA, Hill JT. Patient satisfaction with physician assistants (PAs) in an ED fast track. $A m \mathcal{F}$ Emerg Med 2000;18:661-5, doi:10.1053/ajem.2000.16301.

7. Ellis GL, Brandt TE. Use of physician extenders and fast tracks in United States emergency departments. Am 7 Emerg Med 1997;15:229-32, doi:10.1016/S0735-6757(97) 90002-4.

8. Nyberg SM, Waswick W, Wynn T, et al. Midlevel providers in a level I trauma service: experience at Wesley medical center. 7 Trauma 2007;63:128-34, doi:10.1097/01.ta. 0000221765.90190 .73 .

9. Jones I, Hooker R. Physician assistants in Canada: a health policy initiative. Can Fam Physician 2011;57:e83-e88.

10. Ducharme J, Alder RJ, Pelletier C, et al. The impact on patient flow after the integration of nurse practitioners and physician assistants in 6 Ontario emergency departments. CFEM 2009;11:455-61.

11. Larkin GL, Hooker RS. Patient willingness to be seen by physician assistants, nurse practitioners and residents in the ED: does the presumption of consent have an empirical basis? Am $\mathcal{f}$ Bioethics 2010;10:1-10, doi:10.1080/ 15265161.2010.494216.

12. Hooker RS, Harrison K, Pashen D. Are Australians willing to be treated by a physician assistant? Australas Med 7 2010;3: 407-13, doi:10.4066/AMJ.2010.325.

13. Doan QD, Hooker RS, Wong H, et al. Canadians' willingness to receive care by physician assistants. Can Fam Physician 2012;58:e459-64.

14. Doan Q, Sabhaney V, Kisson N, et al. The role of physician assistants in a pediatric emergency department: a center review and survey. Pediatr Emerg Care 2012;28:783-8, doi:10.1097/ PEC.0b013e3182627ce5.

15. Firth D. Bias reduction of maximum likelihood estimates. Biometrika 1993;80:27-38, doi:10.1093/biomet/80.1.27.

16. Moser M, Abu-Laban R, van Beek C. Attitude of emergency department patients with minor problems to being treated by a nurse practitioner. Can 7 Emerg Med 2004;6:246-52.

\section{APPENDIX: WHAT IS A PHYSICIAN ASSISTANT?}

Physician assistants (PAs) are highly skilled health professionals who perform tasks similar to those performed by their physician supervisors, including 
examination, diagnosis, testing, referrals, and treatment, including prescribing. In Canada, the PA role was developed within the Canadian Forces Health Services to provide a full spectrum of medical care to its members. In 2003, the Canadian Forces PA program was accredited by the Canadian Medical Association. New training programs have been set up in Manitoba and Ontario.

PAs have been a safe and effective part of the US health system for over 40 years. The US experience, with approximately 63,000 PAs currently in practice and 139 accredited training programs, has yielded ample data on the effectiveness, patient acceptability, and safety of PA care.

The success of PAs in the Canadian Forces, early reports from civilian PA practice, and the growth of provincial initiatives tell us that PAs are a viable solution to reducing waiting times and increasing access to care in a timely, safe, and cost-effective manner. 